\title{
LANGUAGE LEARNING AUTONOMY AND ACTION RESEARCH
}

\author{
MV. Joyce Merawati \\ English Dept, Politeknik Negeri Bandung, Indonesia
}

\begin{abstract}
This study attempts to explore the development of learning autonomy of seventeen Civil Engineering students at a state polytechnic in Indonesia when learning English as a foreign language by conducting inductive action research together with the students and was supported by the managing staff of SelfAccess Language Learning (SALL). The development was analyzed from learners' journals, observations, and class discussion or small talks. The results showed that conducting action research with the students for two semesters develops language learning autonomy in various degrees moving from physical to cognitive behaviors.
\end{abstract}

Keywords: learning autonomy, action research, Self-Access Language Learning (SALL)

\section{Introduction}

One of the goals of education is to build students' learning autonomy or individuals'ability to decide what they think (Boud, 1988 in Benson and Voller, 1997). Autonomy cannot be learnt within a short time and total autonomy is an ideal but it is rarely reached (Gardner and Miller, 1999). This study attempted to develop the students' autonomy in language learning by applying inductive action research when they were studying English as a foreign language, particularly in reading class, at Politeknik Negeri Bandung, Indonesia. This paper briefly discusses autonomous learners' characteristics, promoting learning autonomy, and action research; in addition, a program and the results are also presented.

\section{The Characteristics of Autonomous Learners}

Learning autonomy in this study is defined as the students' ability to make decision about what to learn and how to manage their learning to achieve their objectives. Autonomous learners are those who are able 'to take charge of their own learning' (Holec, 1981 cited in Gardner and Miller, 1999). Benson (2001) prefers to define it as those who have 'the capacity to take control of their own learning'. In philosophy and psychology, autonomy has come to be associated with the capacity of the individual to act as a responsible member of society since learners cannot be independent from one another (Benson and Voller, 1997). In order to have relatedness with their learning environment, learnershave to regulate themselves in two levels i.e. being reactive and proactive (Littlewood, 1999). They are able to orchestrate various learning strategies.and act as the managers of their own learning (Holec, 1987) i.e. They know what to learn, with what materials, how to learn, and reflect to assess the outcomes.

Autonomous learners have clear learning purposes i.e. communicative competence (Holec, 1979). They have strong motivation, high level of confidence, adequate knowledge 
and skills (Littlewood, 1996). They are capable of identifying their problems and learning to solve their problems (Ridley, 1997). They establish personal agendas for learning, set up directions, set clear standards of goals, and monitor, control, and motivate themselves to achieve their goals (Pintrich, 2004; Little, 1999; Ridley, 1997). They are flexible and capable of managing, regulating their learning, and using available resources (Breen and Mann, 1997). They make use of various high level cognitive and metacognitive strategies and select suitable materials to achieve their goals and reflect to assess their achievement. They manage learning and feelings by applying appropriate social and affective strategies to increase their motivation, and to control their nervousness.

However, the less autonomous learners prefer to learn the language incidentally (Smith, 1988 in Ridley, 1997). They have unclear learning purposes and low extrinsic motivation. They do not develop their learning strategies (Porte, 1990, in Griffiths, 2003), and apply low-level cognitive strategies (Littlejohn, 1997). They are teacher dependent and expect teachers to assign, correct homework, and explain grammar.

\section{Promoting Learning Autonomy}

Many experts find that learning autonomy can be enhanced by means of learner-centered approach and providing learning strategy training (Nunan, 1996; Dam, 1998; Cohen, 2003). Learner-centered approach is different from traditional approach forit requires teachers and learners to collaborate in the decision-making process. This approach needs several proceedingsas suggested by Nunan (1996):

1. Collecting data about the learners to diagnose their objective needs (Richterich, 1972 in Nunan, 1996).

2. Selecting content and material by making explicit the content objectives of a course and by training learners to set objectives. This encourages them to have a more realistic goal, see their needs, and develop their learning skills and strategies.

3. Negotiating the methodology

4. Conducting evaluation at various times.

5. Promoting learners' self-evaluation. Learners may evaluate the materials, learning activities, and their own achievement.

This approach allows teachers to teach both specific language skills and learning strategies i.e. to encourage them to adopt realistic goals, develop skills to negotiate, provide learners with efficient learning strategies, help them identify preferred ways of learning, and reflect to self-evaluate their achievement (Nunan, 1996). As the course goes on, the students develop their awareness, and the good relationship between the students and the teacher is established, the program can be modified because the most valuable learners' data are obtained in an informal way after relationships between the students and the teacher have been established(Nunan, 1996).

Dam (1998) provides some steps; at the beginning teacher direct students to reflect by gathering learning experiences and evaluating, then planning carrying out plans and finally reevaluating. In each stage, learners are advised to answer reflective questions such as 'what did I do?' 'How did I do it? 'What are the problems? 'What are the achievements? 'What are the next steps? 'These questions help learners diagnose their strengths and weaknesses, 
become aware of what helps them learn the target language efficiently, perceive their problems, develop a broad range of problem-solving strategies, make decisions, monitor, evaluate and transfer the successful strategies (Cohen, 2003).

Learners are also allowed to practice and experience the advantages of systematically applying the strategies to the learning and use of the language they are studying (Cohen, 2003). At this stage generally learners' journals have been promoted as vehicles for reflection and self-evaluation (Kent, 1997 and Moon, 1999 as cited in Little, 2007). Writingjournals and selfreports are highly conscious and direct learners to think deeply, internalize and use the language and strategy learned.

In addition, learners are advised to look for opportunities to share their preferred strategies with others and to increase the use of their strategies (Cohen, 2003). By sharing their strategies orally to their friends and class, learners are able to adopt other strategies learned from their friends and use the language authentically (Little, 2007).

To promote learning autonomy, a teacher has roles to help students be active in learning. Teacher's tasks are to set up dialogues, reorganize and refashion learners' prior knowledge and strategies to help learners reach their potential cognitive levels (Gardner and Miller, 1999). A teacherwarmly acts as a guide, facilitator of learning, a counselor, and as a resource (Benson, 2001). She/he guides learners set objectives, plan, select materials and organize interaction, evaluate, and acquire the skills and knowledge (Voller, 1997). However, when the learners' activities are leading them into 'blind alley' especially when they fail to set themselves 'optimal challenges', a teacher has the responsibility to intervene (Little, 2007).

These activities are strengthened and put into practice in the framework of inductive action research, in which the teacher together with the learners may negotiate the various needs, interests and goals; and then plan, carry out the plan and evaluate together.

\section{Action Research}

Action research models a process of reflective cycle on professional action (Wallace, 1998). It focuses on problems and aims at solving problems (Carr and Kemmis, 1986; Cohen, 2007; Stringer, 1996). The main characteristic of action research is the spiral activity consisting of planning, acting, observing, and reflecting (Kemmis and McTaggart, 1988, as cited in Stringer, 1996). Action research has two types of inquiries - inductive and deductive(Wallace, 1998).Inductive action research is conducted when the inquiry is derived from data collection; on the other hand, when the inquiry is to apply the principles of good teaching methodology, deductive action research is carried out.

The inductive action research, to some extent, is matched well with learner-centered approach for at least six reasons: first, the inductive action research starts with need analysis to discover the problems conducted by the teacher together with the students and followed with actions to solve the problems based on the students' needs, interests and wants. Second, it has two approaches - individual and collaborative approach (Wallace, 1998). It allows the classroom teacher to collaborate with the students because it can be undertaken by individual teachers as well as a group of teachers working together within one school etc. (Cohen, et.al, 2007). Third, it has cycles which each consists of plan, act, observe and reflect (Carr and 
Kemmis, 1986) and each cycle can be the modification or refinement of the previous ones (Stringer, 1996). These help the students manage and control their learning. Fourth, action research, particularly the community-based action research, can be conducted based on everyday life activities by a group of people in collaboration to assist others in extending their understanding of their situation and thus resolves problems (Stringer, 1996).Fifth, it is employed in anticipation of some changes (Stringer, 1996; Wallace, 1998) because the changes of each cycle could be compared and the paths of development could be investigated. This allows the students reflect and evaluate their development. Finally, it allows individual teacher or researcher to control and select appropriate research tools for the teacher's environment and uses these tools to generate the necessary feedback in a systematic way (Cohen, 2007). These allow the teacher to use various data collecting methods and evaluation instruments usually used in the classroom activities. Therefore, inductive action research, which to some extent has some similarities to learner-centered approach, may enhance language learner autonomy.

Since action research allows researchers or teachers to use ordinary instruments and data collecting methods, for students' reflection and evaluation in this study, students' journals - learning log, reflection journals and thinking process journal were used as the main instruments. In addition, classroom discussion, some small talks, and observation noted in researcher's diaries were also used. The small talks and observations were conducted when the students reported their strategies applied to the class or when they had learning activities both in the class and in SALL.

\section{The Program}

One program based on inductive action research was a class of a reading program in Politeknik Negeri Bandung. It was conducted in three cycles and lasted in two semesters. It started with a diagnostic phase and followed with three cycles which each consisted of plan, act, observe and reflect. Diagnostic Phase was to analyze the objective needs, the students' language proficiency, and interests. The results were discussed and considered in 'Plan' stage to select the content and gradation, methodology, materials selections, and evaluation. The 'Plan' stage was followed by a set of treatments or 'Act' in which an ongoing monitoring was carried out. By the end of each cycle an 'Observe and Reflect' stage or assessment was conducted. The program was then evaluated and refined at the next cycles. This program is illustrated in diagram 1. 


\section{Cycle 3}

Cycle 2

\section{Cycle 1}

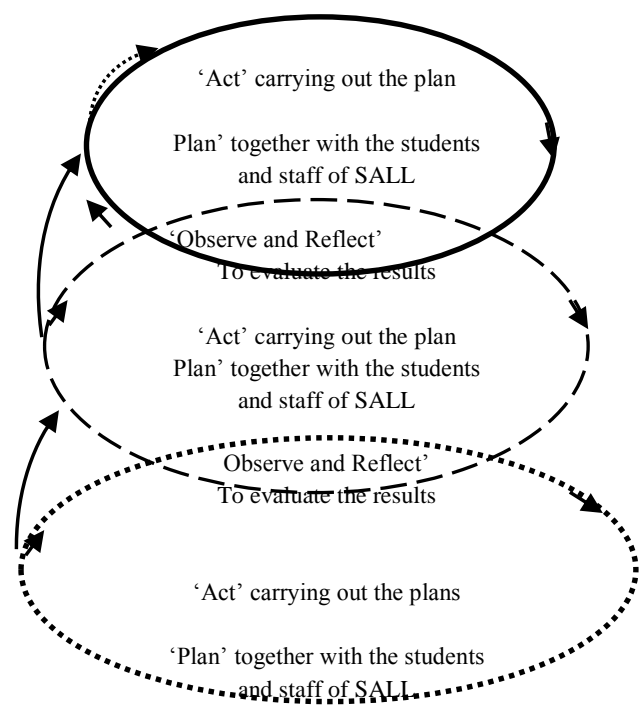

\section{DIAGNOSTIC PHASE}

\section{Diagram 1The Program}

Each cycle consisted of planning, exposures of some strategies, models, discussions and practices (Cohen, 2003) and ended with evaluation as illustrated in Diagram 2.

\section{Observe and reflect}

Act

Plan

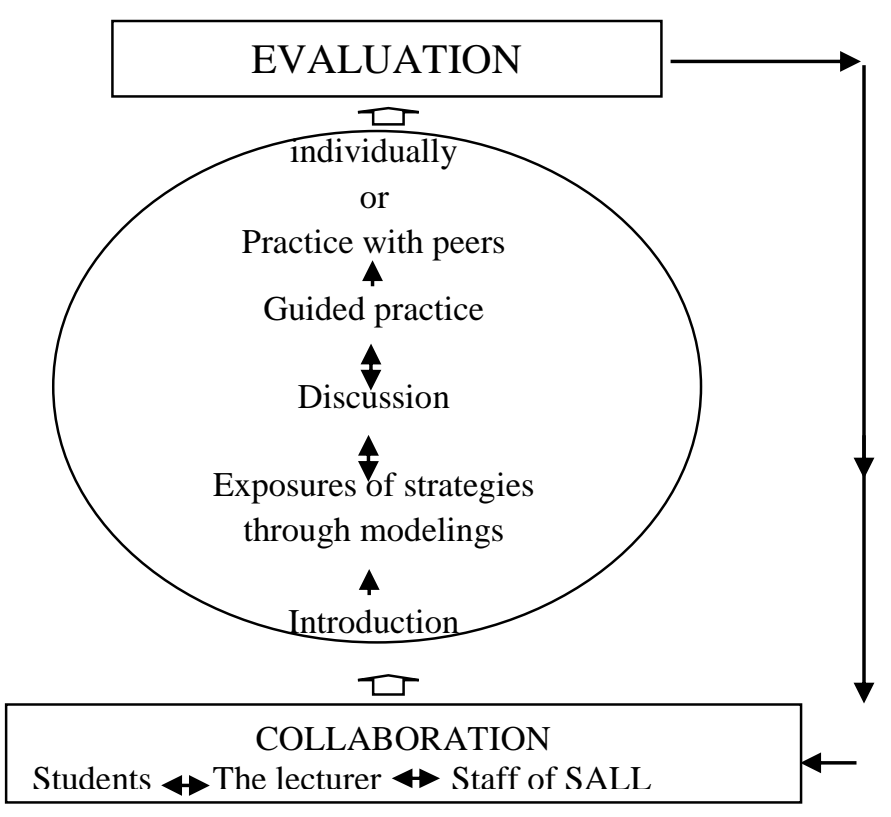

\section{Diagram 2 Treatments of Each Cycle}


Before planning was carried out, feedback on strategies which were applied by the students in the previous cycle was jointly discussed. At 'Plan' stage, the lecturer and students collaborated to develop instructional decision; the students were encouraged to provide suggestions about the materials, the objectives of the cycles, and the learning activities. To guide the students in deciding their learning objectives, the students were encouraged to reflect on their problems in reading English texts or learning English. In preparation for the 'Act', the lecturer collaborated with the managing staff of SALL. During 'Act', exposures to the strategies were provided by the lecturer and models were given either by the lecturer or peers. In this occasion, the students explored various strategies and discovered suitable and personalized strategies. Subsequently the students were instructed to practice the strategies with peers and finally practice individually either in SALL or at home whilst doing their assignments. At the end of each cycle the program were reviewed, evaluated and refined in the next cycles.

This study was conducted in a reading program of 24 first-year civil engineering students, among them 17 students were intensively analyzed because they attended the class, wrote, and submit their journals regularly. When the language learning autonomy were explored from the students' learning purposes, motivation and reading skills particularly their skills for constructing meaning, the results showed that the program enhanced the students' language learning autonomy.

The learners' learning purposes which were analyzed from the students' answers of 'What do you want?' triangulated with those of 'What did you learn?' showed that they developed from physical activities to learning for problem solving. In detail the development moved from enjoyable activities, reading to obtain content information, reading for language learning, improving language starting from easy materials, to learning based on preferences/interests, improving language (vocabulary/grammar) using challenging materials, and finally to solving problems. The last three stages were experienced by the students who had fairly high proficiency only; some of them learned the language by applying top-down approach andothers preferred bottom-up approach. It was also found that learners who applied top-down approach had limited ability to plan, monitor, and evaluate their language. The learners' motivation - represented by their affective response - analyzed from the students' reflective journals improved for various reasons. Their motivation developed from enjoying the learning activities, obtaining language knowledge , being able to apply learning strategies, developing thinking, finding and solving problems, applying imagination and creativity, expressing ideas, retaining words for longer periods, to being capable of doing challenging exercises and learning independently. The skills for constructing meanings analyzed from the students' thinking process journals developed in three clusters: typography of texts, analyzing, classifying words, and synthesizing meanings from other words, and finally relating meaning to the wider scope of contexts.

These results showed that the development of students' learning autonomy were in line with the levels of language proficiency and learning purposes. When they focused on enjoyment activities, they did not apply their high level of cognitive strategies to learning the language. However, when they had language learning purposes, they then thought deeply and as a result they learned and acquired the language. 


\section{Conclusion}

Autonomous learners are those who are capable of managing and responsible for their learning. They are able to orchestrate various learning strategies,set realistic goals, select materials and learning methods, and evaluate the outcomes. Learning autonomy can be developed by means of learner-centered approach which requires lecturers to collaborate with the students throughout the program. It has several steps, diagnose the students' needs, interests and lacks, selecting learning content and materials, negotiating the methodology, and conducting evaluation. This approach matches well with the inductive action research providing that the research is conducted by the teacher or a group of teachers together with the students. After conducting this study in two semesters in an English reading class of Civil Engineering students at Politeknik Negeri Bandung, Indonesia, the students' learning autonomy developed from physical to cognitive behaviors.

\section{References:}

- Benson, P. (2001)Teaching and Researching Autonomy in Language Learning. England: Pearson Education Limited.

- Benson, P., and Voller, P. (1997)Autonomy and Independence in Language Learning, New York: Longman

- Breen, M.P. and Mann, S.J. (1997) Shooting arrows at the sun: Perspectives on a pedagogy for autonomy, in Autonomy and Independence in Language Learning, Benson and Voller, eds, 1997, London: Pearson Education Limited.

- Carr, W and Kemmis, S. (1986) Becoming Critical: Knowing Through Action Research, Burwood: Deakin University Press

- Cohen, A. (2003) Strategy Training for Second Language Learner, Eric Digest, ED482492

- Cohen, L., Manion, L., \& Morrison, K. (2007) Research Methods in Education (6th Edition ed.). London: Routledge Falmer.

- Dam, L. (1998) Why Focus on Learning rather than Teaching? From Theory to Practice, Focus on Learning rather than Teaching: Why and How? Papers from the IATEFL conference on learner independence, Kraköw, 14 - 16 may 1998, CLCS, Trinity College Dublin 2, Ireland.

- Gardner, D and Miller, L. (1999)Establishing Self-Access: From Theory to Practice. Cambridge: Cambridge University Press.

- Holec, H. (1979)Autonomy and Foreign Language Learning, Strasbourg: Council of the Europe

- Holec, H. (1987) The Learner as Manager: Managing Learning or Managing to learn? InLearner Strategies in Language Learning, Wenden and Rubin, eds, 1987, London: Prentice Hall ELT

- Little, D. (2007) Language Learner Autonomy: Some Fundamental Considerations Revisited, Innovation in Language Learning and Teaching, Vol 1, No 1, 2007

- Littlejohn, A. (1997) Self-Access Work and Curriculum Ideologies, in Benson, Phil and Voller, Peter eds (1997) Autonomy and Independence in Language Learning, United Kingdom: Pearson Education Limited. pp. 181-191 
- Littlewood, W. (1996) Autonomy: an Anatomy and a Framework, System, Vol. 24, pp 427435; Elsevier Science Ltd.

- Littlewood, W. (1999)Defining and Developing Autonomy in East Asian Contexts, Applied Linguistics, 20 (1), pp. 71-94.

- Nunan, D. (1996) The Learner-Centred Curriculum, Cambridge: Cambridge University Press.

- Oxford, R. (1990) Language Learning Strategies. Massachusetts: Heinle \& Heinle Publishers.

- Pintrich, P.R. (2004) A conceptual Framework for Assessing Motivation and SelfRegulated Learning in College Students, Educational Psychology Review, Vol. 16, No. 4 December 2004.

- Ridley, J. (1997)Reflection and Strategies in Foreign Language Learning, Frankfurt, Germany: Peter Lang GmbH.

- Stringer, E.T. (1996) Action Research: A Handbook for Practitioners, New Delhi: Sage Publications

- Victori, M. and Lockhart, W. (1995) Enhancing Metacognitive in Self-directed Language Learning, System, Vol. 23, No. 2: pp 223-234

- Voller, P. (1997) Does the Teacher have a role in Autonomous Language Learning, in Benson, P. and Voller, P. Eds. (1997) Autonomy and Independence in Language Learning, United Kingdom: Pearson Education Limited

- Wallace, M. J. (1998)Action Research for Language Teachers, Cambridge: Cambridge University Press 